\title{
FAKTOR YANG MEMPENGARUHI PEMBENTUKAN KRISTAL URIN PENGKONSUMSI AIR HUJAN DI KELURAHAN GUBUKUSUMA KOTA TIDORE KEPULAUAN
}

\author{
The Factor That Influence The Formation Of Urine Crystals In Rain Water Consumers \\ Of Gubukusuma Village, Tidore Islands City
}

Rony Puasa ${ }^{1}$, Febrianti Jakaria ${ }^{2}$

${ }^{1,2}$ Poltekkes Kemenkes Ternate

Koresponden: rony_yani@yahoo.co.id /081356169179

\begin{abstract}
The use of water for drinking must meet health requirements, water that does not meet health requirements can cause kidney problems with crystal formation. The crystals commonly found in urine are calcium oxalate, triple phosphate, calcium phosphate and uric acid. Gubukusuma Village, Tidore City, Kepulauan, the community still consumes rain water for drinking, bathing and washing. This research was aimed to identify the factors that can influence the formation of urine crystals in rain water consumption in the Gubukusuma Village. The research design used is a combination of survey and laboratory tests with the Cross Sectional Study approach. The research finding showed 56 respondents (39.4\%) contained crystals and 86 respondents $(60.6 \%)$ negative, the highest type of crystal was Oxalate, namely; 29 respondents. Based on the type of gutter, the highest plastic is; 25 respondents (17.6\%), while based on the volume of rainwater consumed, the highest was at $880 \mathrm{ml}$ volume, namely 31 respondents (21.8\%). Based on the length of consumption, the highest among respondents> 20 years of consumption was $43(30.3 \%)$, and based on the highest consumption method, respondents who cooked using a stove were $32(22.5 \%)$. Bivariate analysis to see the relationship between the independent variables of urine crystals with the dependence on where the water flows, the volume of consumption, the duration of consumption and the method of consumption of rainwater, obtained a p-value > 0.05,. Conclusion, $p$ value of the test is greater than 0.05, so there is no relationship between the case of crystal formation in urine with the factors that influence it.
\end{abstract}

Keywords: Urine crystals, rainwater consumption

\begin{abstract}
ABSTRAK
Penggunaan air untuk minum harus memenuhi persyaratan kesehatan, air yang tidak memenuhi persyaratan kesehatan dapat menyebabkan masalah ginjal dengan pembentukan kristal. Kristal yang biasa ditemukan dalam urin adalah kalsium oksalat, triple fosfat, kalsium fosfat dan asam urat. Desa Gubukusuma, Kota Tidore Kepulauan masyarakatnya masih mengkonsumsi air hujan sebagai air minum, mandi, dan mencuci. Tujuan dari penelitian ini adalah mengidentifikasi faktor yang dapat mempengaruhi pembentukan kristal urin dalam konsumsi air hujan di Desa Gubukusuma. Desain penelitian yang digunakan adalah kombinasi dari survei dan tes laboratorium dengan pendekatan Cross Sectional Study. Hasil penelitian menunjukkan 56 responden $(39,4 \%)$ mengandung kristal dan negatif 86 responden $(60,6 \%)$, jenis kristal tertinggi adalah Oksalat yaitu; 29 responden. Berdasarkan jenis talang, plastik paling tinggi yaitu; 25 responden $(17,6 \%)$, sementara berdasarkan volume air hujan yang dikonsumsi, tertinggi adalah pada volume $880 \mathrm{ml}$, yaitu 31 responden $(21,8 \%)$. Berdasarkan lama konsumsi,
\end{abstract}

DOI: https://doi.org/10.32382/mak.v11i2.1619 
tertinggi di antara responden> 20 tahun konsumsi adalah 43 (30,3\%), dan berdasarkan metode konsumsi tertinggi responden yang memasak menggunakan tungku yaitu $32(22,5 \%)$. Analisis bivariat untuk melihat hubungan antara variabel independen kristal urin dengan dependen tempat mengalir air, volume konsumsi, lama konsumsi dan cara konsumsi air hujan.diperoleh uji p-value> 0,05. Kesimpulan, tidak ada hubungan antara kasus pembentukan kristal dalam urin dengan tempat mengalir air, volume konsumsi, lama konsumsi dan cara konsumsi air hujan.

Kata kunci; Kristal urin, konsumsi air hujan

\section{PENDAHULUAN}

Air merupakan kebutuhan penting bagi mahluk hidup di muka bumi, terutama bagi manusia. Air berperan dalam segala bidang yaitu pertanian, industri, dan pemenuhan kebutuhan rumah tangga, sehingga air yang digunakan harus memenuhi standar ataupun syarat dari segi kualitas maupun kuantitas. Air yang bersih dan sehat merupakan kualifikasi yang sangat diperlukan untuk pemenuhan kebutuhan tersebut. (Strasinger, Susan dan Lorenzo, Marjorie. 2017).

Menurut Permenkes Nomor ; 92/ Menkes/Per/IV/2010 tentang persyaratan kualitas air Minum, air minum aman bagi kesehatan apabila memenuhi persyaratan fisika, mikrobiologis, kimiawi dan radioaktif yang dimuat dalam parameter wajib dan parameter tambahan. Penyakit-penyakit yang menyerang manusia dapat ditularkan dan disebarkan melalui air. Penyakitpenyakit tersebut merupakan akibat semakin tingginya kadar pencemar yang memasuki air, (Dinas Kesehatan Kota Tidore,2018)

Di Indonesia propinsi yang paling banyak menggunakan air hujan sebagai sumber air minum antara lain Kalimantan Barat, Riau, Papua, Jambi dan Papua Barat. Berdasarkan data Riskesdas 2013 presentase air hujan yang dikonsumsi masyarakat kota dan desa untuk air minum yaitu daerah perkotaan sebesar 2,3\% sedangkan daerah pedesaan sebesar $4,8 \%$.

Air hujan hampir tidak mengandung kontaminasi. Oleh karena itu air tersebut sangat bersih dan bebas kandungan mikroorganisme. Namun ketika air hujan tersebut kontak dengan permukaan tangkap air hujan (cathcment), tempat mengalir air hujan (conveyance), dan tangki penampung air hujan, maka air tersebut akan membawa kontaminasi fisik, kimia maupun mikrobiologi.

Kontaminan kimia seperti ; amonia $\left(\mathrm{NH}_{3}\right)$, asam sulfit (SO2), nitit $\left(\mathrm{NO}_{3}\right)$ dan garam. Amonia yang tinggi dalam urine akan merangsang terbentuknya kristal tripel fosfat dan amonium biurat, sedangkan $\mathrm{SO}_{2}$ akan berikatan dengan kalsium (Ca) dalam tubuh membentuk kristal kalsium oksalat. (Strasinger, Susan dan Lorenzo, Marjorie. 2017).

Kelurahan Gubukusuma Kecamatan Tidore Utara Kota Tidore Kepulauan merupakan salah satu kelurahan yang masyarkatnya masih mengkonsumsi air hujan sebagai air minum, mandi dan mencuci. Ketersediaan Air bersih bagi penduduk, oleh Pemerintah Kota Tidore Kepulauan sejak tahun 1985 namun belum menjangkau Kelurahan Gubukusuma. Hal ini disebabkan Kelurahan Gubukusuma terletak didaerah ketinggian yang belum bisa dijangkau untuk pemasangan pipa saluran air bersih.

Masyarakat Kelurahan Gubukusuma bervariasi dalam kepemilikan baik ; tempat tangkap air hujan, tempat aliran air hujan dan bak penampungan air hujan. Tangkapan air hujan ada terbuat dari seng dan rumbia, tempat aliran air hujan ada terbuat dari plastik dan bambu, serta penampungan air hujan yang terbuat dari beton dan drum plastik. Hal ini dapat berpengaruh pada air yang akan dikonsumsi.

Penggunaan air untuk minum hendaknya bersih dan sehat, sebab penggunaan air yang tidak memenuhi syarat 
kesehatan, dapat menyebabkan gangguan kesehatan salah satunya adalah gangguan ginjal yang disebabkan oleh peningkatan kristal.

\section{METODE}

\section{Desain, tempat dan waktu}

Desain penelitian yang digunakan adalah kombinasi antara survey dan uji laboratorik dengan pendekatan "Cross Sectional Study " atau studi potong lintang, yang mana data primer dari variabel independen dan dependen diperoleh dalam waktu bersamaan.

Lokasi penelitian adalah Kelurahan Gubukusuma Kecamatan Tidore Utara , Kota Tidore Kepulauan, sedangkan pemeriksaan dilakukan di laboratorium terpadu Poltekkes Kemenkes Ternate. Penelitian dilaksanakan pada Agustus s/d November 2019.

\section{Polulasi dan Sampel}

Populasi adalah seluruh masyarakat yang mengkonsumsi air hujan di Kelurahan Gubukusuma yang berjumlah 1.019 jiwa pada 8 RT (Rukun Tetangga) dengan 220 Kepala Keluarga (KK).

Sampel digunakan pada penelitian ini adalah urin masyarakat Kelurahan Gubukusuma Kecamatan Tidore Utara pengkonsumsi air hujan yang diambil secara random (acak), dari Kepala Keluarga (KK) atau anggota keluarga sebagai unit sampel. Kriteria sampel yang digunakan adalah Tidak memiliki riwayat penyakit ginjal, Masyarakat yang berusia 17 - 54 tahun.

Besaran sampel dari jumlah populasi sebanyak $220 \mathrm{KK}$, maka peneliti mengambil jumlah sampelnya sebanyak 142 sampel, dimana 1 sampel mewakili $1 \mathrm{KK}$. besarnya sampel menggunakan rumus Slovin dengan tingkat kesalahan 5\%.

\section{Prosedur Kerja Pemeriksaan Urin}

Menurut R.Gandasoebrata Pemeriksaa Urin Sedimen dilakukan dapat dilakukan secara semikuantitatif

\section{Persiapan Alat dan Bahan} mikrskop, centrifuge, rak tabung, urin, tabung centrifuge, pot urin, pipet tetes, objek glass, deck glass, handscoon . masker.

2. Cara Kerja

Pemeriksaan mikroskopik urin adalah:

a. Dihomogenkan terlebih dahulu sampel urin

b. Masukan $10 \mathrm{ml}$ urin dalam tabung centrifuge dan diputar selama 5 menit kecepatan 1500-2000 rpm

c. Setelah sentrifuge, tuanglah urine sehingga didapatkan sedimen urin

d. Kocok tabung untuk mensuspensikan sedimen

e. Ambil suspensi sedimen dengan pipet tetes

f. Letakkan 1-2 tetes di atas objek glass dan ditutup dengan deck glass

g. Periksa menggunakan mikroskop dengan pembesaran awal lensa objektif 10x, kemudian dilanjutkan dengan pembesaran objektif 40x

\section{Pengolahan Data}

Pengolahan Data; data sebelum diolah menggunakan computer dengan program SPSS, data dikumpulkan melalui wawancara langsung dan pengamatan terhadap responden dan lingkungan.

\section{Analisa Data}

Analisa data menggunakan uji statitik Chi square dengan tingkat kemaknaan $\quad \alpha=0.05$

\section{HASIL}

Perolehan hasil penelitian ini merupakan data - data yang dikumpulkan saat penelitian berupa, hasil pemeriksaan urine secara mikroskopis dan observasi lingkungan serta wawancara subjek yang tinggal di Kelurahan Gubukusuma Kecamatan Kota Tidore Utara. Urine yang diambil dari subjek sebanyak 142 sampel. kemudian dimasukan kedalam tabung centrifuger sebanyak $10 \mathrm{ml}$ dan di pusingkan selama 5 menit dengan kecepatan 2000 RPM (Round Perminut), dan selanjutnya 
diidentifikasi menggunakan mikroskop dengan pembesaran $400 \mathrm{x}$.

\section{Analisa Univariat}

Setelah diperoleh hasil identifikasi mikroskopis kemudian dianalisa menggunakan Chi square dengan melakukan uji silang (crosstab ) terhadap hasil wawancara pada responden, maka diperoleh hasil penelitian sebagai berikut ;

Tabel 1,setelah sampel urine diidentifikasi diperoleh hasil $56(39,4 \%)$ responden dalam urine mengandung kristal, dan $86(60,6 \%)$ tidak mengandung kristal.

Tabel 2, menggambarkan hasil identifikasi sampel urine responden tertinggi adalah jenis kristal Calsium Oksalat yakni ; $29(20,4 \%)$ dan terendah adalah jenis kristal Tripel Fosfat yakni ; 1 responden $(7 \%)$, serta 2 responden $(1,4 \%)$ dalam urine mengandung campuran antara kristal Tripel Fosfat dan Asam Urat, sedangkan 86 responden $(60,6 \%)$ didalam urine tidak mengandung kristal.

Tabel 3, menggambarkan responden yang didalam urinenya mengandung kristal tertinggi yakni 25 $(17,6 \%)$ adalah jenis tempat mengalir air hujan (talang) yang terbuat dari plastik dan terendah terbuat dari bambu yakni 16 $(11,3 \%)$.

Tabel 4, menggambarkan
responden yang didalam urinenya mengandung kristal tertinggi yakni 31 $(21,8 \%)$ adalah pada pengkonsumsi air hujan terbanyak (880 ML), dan dalam urinenya tidak mengandung kristal juga terdapat pada pengkonsumsi air hujan terbanyak yakni 46 $(32,4 \%)$.

Tabel.5, responden yang didalam urinenya mengandung kristal tertinggi yakni 43 $(30,3 \%)$ adalah pada pengkonsumsi air hujan terlama (>20 tahun), dan dalam urinenya tidak mengandung kristal juga terdapat pada pengkonsumsi air hujan terlama yakni 76 $(53,5 \%)$.
Tabel 6, menggambarkan responden yang didalam urinenya

mengandung kristal tertinggi yakni 32 $(22,5 \%)$ adalah pada pengkonsumsi air hujan yang di masak menggunakan tungku (kayu yang dibakar), dan dalam urinenya tidak mengandung kristal terdapat pada pengkonsumsi air hujan yang dimasak menggunakan kompor yakni 47 (33,1\%).

\section{Analisa Bivariat}

Tabel 7, yang merupakan hasil Uji Pearson diperoleh nilai $p=0,874>0,05$. Hal ini menunjukan Ho diterima dan Ha ditolak, dengan demikian maka tidak ada hubungan antara adanya kristal dalam urine responden dengan jenis tempat mengalirnya air hujan (talang).

Tabel 8, yang merupakan hasil Uji Pearson diperoleh nilai $\mathrm{p}=0,827>0,05$. Hal ini menunjukan Ho diterima dan Ha ditolak, dengan demikian maka tidak ada hubungan antara adanya kristal dalam urine responden dengan volume air hujan yang dikonsumsi.

Tabel 9, yang merupakan hasil Uji Pearson diperoleh nilai $p=0,067>0,05$. Hal ini menunjukan Ho diterima dan Ha ditolak, dengan demikian maka tidak ada hubungan antara adanya kristal dalam urine responden dengan lamanya konsumsi air hujan.

Tabel 10, yang merupakan hasil Uji Pearson diperoleh nilai $\mathrm{p}=0,170>0,05$. Hal ini menunjukan Ho diterima dan Ha ditolak, dengan demikian maka tidak ada hubungan antara adanya kristal dalam urine responden dengan cara konsumsi air hujan.

\section{PEMBAHASAN}

Salah satu jenis air yang masih digunakan manusia sebagai penunjang kehidupan adalah air hujan. Air hujan menjadi air yang menyegarkan dan aman untuk digunakan dalam aktifitas sehari-hari seperti, mandi bahkan untuk di konsumsi. Namun ada juga beberapa aktifitas manusia yang tidak bisa menggunakan air hujan. Hal tersebut karena air hujan memiliki beberapa kandungan zat yang tidak baik untuk aktifitas manusia. Kandungan air hujan ini termasuk kedalam zat yang bersifat kimiawi. Beberapa zat kimia yang terkandung dalam 
air hujan seperti ; uap air (H2O), Asam Nitrat, Karbon, Asam Sulfat dan Garam, (Hardjoeno dan Fitriani. 2017). Air hujan dapat menyebabkan gangguan kesehatan, hal ini disebabkan oleh air hujan yang telah terkontaminasi dengan polutan yang ada diudara, terutama pada daerah - daerah dengan tingkat polusi yang tinggi. Selain polutan udara sumber lain yang dapat menyebabkan penyakit adalah penadah air hujan yang telah terkontaminasi dengan mikroorganisme patigen, , (Arianda, 2017).

Dari hasil penelitian yang telah dianalisa menggunakan Uji Pearson untuk melihat hubungan yang bermakna antara variabel independen dengan dependen yakni ; adanya kristal dalam urine responden dengan jenis tempat mengalir air hujan (talang), volume konsumsi air hujan, lamanya konsumsi air hujan, dan cara konsumsi, menggambarkan tidak ada hubungan yang bermakna antara kedua variabel tersebut.

Hal ini menunjukan air hujan yang dikonsumsi masyarakat Kelurahan Gubukusuma Kota Tidore Kepulauan tidak berhubungan langsung dengan terbentuknya kristal dalam urine. Namun terbentuknya kristal dalam urine responden dapat disebabkan oleh faktor lain. Beberapa faktor yang dapat membentuk kristal dalam urine antara lain ; faktor keturunan atau bawaan, jenis kelamin, suhu, jumlah asupan air, aktifitas serta obat-obatan.

Faktor dominan yang mungkin dapat menyebabkan terbentuknya kristal dalam urine pada responden adalah tingginya aktifitas mereka dan kurangnya asupan air. Aktifitas tinggi dari responden disebabkan oleh pekerjaan mereka sebagai petani. Petani di Kelurahan Gubukusuma adalah petani yang bertani pada kebun yang harus menggunakan tenaga untuk mencangkul.

Melakukan aktifitas yang tinggi namun kurang asupan air dapat menyebabkan kekurangan cairan pada ginjal sehingga urine dapat menjadi pekat yang menyebabkan terbetuk kristal yang lama kelamaan akan menjadi batu ginjal. Masyarakat Kelurahan Gubukusuma yang bekerja sebagai petani mereka bekerja dari pagi hingga sore di kebun bila dibekali dengan air yang tidak sesuai dengan kebutuhan asupan, ini dapat mempengaruhi terbentuknya kristal dalam urine.

Hal lain yang dapat dilihat dari Kelurahan Gubukusuma, kelurahan ini terletak di daerah pegunungan dengan disekitar lingkungan masih ditumbuhi pohon yang rindang, sehingga cemaran udara masih dinetralisir oleh adanya pepohonan. Keadaan ini dapat meminimalisir pencemaran udara terhadap kualitas air hujan yang dikonsumsi. Dilihat dari jumlah kendaraan yang dapat menyebabkan polusi udara Kota Tidore masih rendah.

Dengan tingkat pencemaran yang rendah, maka baik udara, penangkap air hujan, tempat mengalirnya air hujan serta bak penampungannya dapat berdampak pada responden, sehingga walaupun sudah $>20$ tahun mengkonsumsi air hujan dengan volume $660 \mathrm{ml}-880 \mathrm{ml}$ tetapi tidak berhubungan yang signifikan dengan terbentuknya kristal dalam urinenya.

Dilihat dari jenis kristal pada urine responden seperti pada tabel 5.2 terdapat 29 $(20,4 \%)$ adalah mengandung kristal Casium Oksalat. Pembentukan kristal ini dapat bersumber dari faktor konsumsi antara lain bila mengkonsumsi yang berlebihan baik itu tumbuhan dan hewan, sedangkan dari manusia itu sendiri dimna dalam tubuh dapat memecahkan vitamin $\mathrm{C}$ menjadi asam oksalat. Dengan adanya mineral kalsium dalam tubuh akan membentuk kristal Calsium Oksalat yang berbentuk seperti jarum.

Dengan adanya kristal pada 56 responden (39.4\%) di Kelurahan Gubukusuma perlu menjadi perhatian walaupun telah diuji secara statistik tidak menunjukan hubungan, namun ini perlu di berikan pemahaman sehingga dapat mencegah terjadi faktor - faktor terbetuknya kristal sebelum kristal-kristal tersebut 
mengendap menjadi batu ginjal yang dapat mengganggu fungsi ginjal.

\section{KESIMPULAN}

Berdasarkan hasil penelitian yang telah dilaksanakan dan dilakukan uji statistik Pearsion, maka dapat disimpulkan penelitian ini adalah ;

1. Tidak terdapat hubungan yang bermakna antara terbentuknya kristal urine dari responden dengan jenis tempat mengalir air hujan (talang)

2. Tidak terdapat hubungan yang bermakna antara terbentuknya kristal urine dari responden dengan volume air hujan yang dikonsumsi

3. Tidak terdapat hubungan yang bermakna antara terbentuknya kristal urine dari responden dengan lamanya konsumsi air hujan

4. Tidak terdapat hubungan yang bermakna antara terbentuknya kristal urine dari responden dengan cara mengkonsumsi air hujan

\section{SARAN}

Dari kesimpulan penelitian yang telah dilakukan dan analisa secara ilmiah, maka dapat disarankan ;

1. Kepada pihak Kelurahan Gubukusuma Kota Tidore Kepulauan agar selalu memberikan pemahaman kepada masyarakat untuk tetap membersihkan saluran air hujan dan bak penampungan air hujan.

2. Kepada Pemerintah Kota Tidore Kepulauan agar segera dapat mempercepat proses pemasangan air bersih yang layak untuk dikonsumsi.

3. Untuk teman - teman peneliti selanjutnya dapat melakukan penelitian lanjutan dari bidang mikrobiologi untuk melihat kualitas air hujan yang dikonsumsi masyarakat Kelurahan Gubukusu.

\section{UCAPAN TERIMA KASIH}

Terima kasih saya ucapkan kepada Direktur Poltekkes Kemenkes Ternate yang telah memberikan kesempatan dan anggaran sehingga terlaksananya penelitian ini ,

\section{DAFTAR PUSTAKA}

Arianda Dedy., Kimia Klinik Seri I sistem urinaria dan pemeriksaan urinalisa, Bekasi, AM-Publishing, 2015.

E.Kosasih, Tafsiran Hasil Pemeriksaan Laboratorium Klinik Edisi Kedua. Jakarta: Buku Kedokteran EGC, 2008.

H. Effendi, Telaah Kualitas Air bagi Pengelolaan Sumber daya dan Lingkungan Perairan. Yogyakarta: Kanisius, 2010.

Obiet, "Perbedaan sedimen urine pada masyarakat yang mengkonsumsi air pegunangan RRI lama dan Jalan Lasolo, Kota Kendari," Bina Husada, 2014.

P. M. K. N. 492/menkes/PER/IV/2010 tentang P. kualitas air Minum, "No Title."

R. Gandasoebrata, Penuntun Laboratorium Klinik. Jakarta: Dian Rakyat, 2006. [14]

R. Siener, A. Jahnen, and A. Hesse, "Influence of a Mineral Water Rich in Calcium, Magnesium and Bicarbonater on urine Compostion and The Risk of calcium Oxalate crystallization," Eur K.Clin.Nutr, vol. 58, pp. 270-276, 2004.

Ruth Mongan1*, Supiati2, Susi Mangiri3 "Gambaran Sedimen Urine Pada Masyarakat Yang Mengkonsumsi Air Pegunungan Di Kecamatan Kendari Barat Kota Kendari”, Jurnal Teknologi Laboratorium, Maret 2017, Vol.6, No.1, Maret, pp. $18 \sim 24$

R. Yunus and T. Yuniarti, "Gambaran Hasil Pemeriksaan Kristal Urin Orang Yang meminum Air Minum Kemasan isi Ulang (air Galon) dan orang meminum air minum dari sumur gali," Meditoty J., Juni 2016, vol. 4, no. 1, pp. 1-6,

Strasinger, Susan dan Lorenzo, Marjorie. 2017. Urinalisis dan Cairan Tubuh. EGC Suparno, 2013, Usaha Penyediaan dan Pengolahan Air Bersih di Wilayah Perkotaan Secara Terpadu, Orbith ; 9.2.10-4. 
U. Suriawiria, Mikrobiologi Air dan Dasardasar Pengolahan Buangan Secara Biologis. Bandung: Penerbit Alumni, 2008. 
Tabel 01

Distribusi dan Frekuensi Identifikasi Mikroskopis Urin

Responden

\begin{tabular}{lcc}
\hline & Jumlah & \% \\
\hline Positif & 56 & 39.4 \\
\hline Negatif & 86 & 60.6 \\
\hline Total & 142 & 100 \\
\hline
\end{tabular}

(Sumber ; data primer)

Tabel 02

Distribusi dan Frekuensi Kristal Urin Responden Berdasarkan Jenis

\begin{tabular}{|c|c|c|c|}
\hline \multirow{6}{*}{ Positif } & & Jumlah & $\%$ \\
\hline & Ca. Oksalat & 29 & 20,4 \\
\hline & Tripel Fosfat & 1 & 7 \\
\hline & Asam Urat & 4 & 2,8 \\
\hline & $\begin{array}{l}\text { Mix (Tripel Fosfat dan } \\
\text { As, Urat) }\end{array}$ & 2 & 1,4 \\
\hline & Kristal lain & 20 & 14,1 \\
\hline Negatif & & 86 & 60,6 \\
\hline Total & & 142 & 100 \\
\hline
\end{tabular}

(Sumber ; data primer)

Tabel 03

Distribusi dan Frekuensi Adanya Kristal Pada Urin Responden Berdasarkan Jenis Tempat Mengalir Air Hujan (Talang)

\begin{tabular}{|c|c|c|c|c|c|c|c|}
\hline & \multicolumn{2}{|c|}{ Seng } & \multicolumn{2}{|c|}{ Plastik } & \multicolumn{2}{|c|}{ Bambu } & \multirow[b]{2}{*}{ Total } \\
\hline & Jumlah & $\%$ & Jumlah & $\%$ & Jumlah & $\%$ & \\
\hline Positif & 15 & $\begin{array}{c}10 \\
5\end{array}$ & 25 & 17,6 & 16 & 11,3 & 56 \\
\hline Negatif & 21 & $\begin{array}{c}14 \\
8\end{array}$ & 38 & 26,8 & 27 & 19 & 86 \\
\hline Total & 39 & $\begin{array}{c}27 \\
4\end{array}$ & 61 & 41,6 & 43 & 31 & 142 \\
\hline
\end{tabular}

(Sumber ; data primer) 
Tabel 04

Distribusi dan Frekuensi Adanya Kristal Pada Urin Responden Berdasarkan Volume Konsumsi Air Hujan

\begin{tabular}{lccccc}
\hline & \multicolumn{3}{c}{ Volume Air Hujan yang di Konsumsi } & \multirow{2}{*}{ Total } \\
\cline { 2 - 5 } & \multicolumn{2}{c}{$\mathbf{8 8 0}$ ML } & \multicolumn{2}{c}{$\mathbf{6 6 0}$ Ml } & \\
\hline & Jumlah & \% & Jumlah & $\%$ & \\
\hline Positif & 31 & 21,8 & 25 & 17,6 & 56 \\
\hline Negatif & 46 & 32,4 & 40 & 28,2 & 86 \\
\hline Total & 77 & 54,2 & 65 & 45,8 & 142 \\
\hline
\end{tabular}

(Sumber ; data primer)

Tabel 05

Distribusi dan Frekuensi Adanya Kristal Pada Urin Responden Berdasarkan Lama Konsumsi Air Hujan

\begin{tabular}{lccccc}
\hline & \multicolumn{3}{c}{ Lama Konsumsi Air Hujan } & \multirow{2}{*}{ Total } \\
\cline { 2 - 5 } & $\mathbf{1 0}-\mathbf{2 0}$ tahun & \multicolumn{2}{c}{$>$ 20 tahun } & \\
\hline & Jumlah & $\mathbf{\%}$ & Jumlah & $\mathbf{\%}$ & \\
\hline Positif & 13 & 9,2 & 43 & 30,3 & 56 \\
\hline Negatif & 10 & 7 & 76 & 53,5 & 86 \\
\hline Total & 23 & 16,2 & 119 & 83,8 & 142 \\
\hline
\end{tabular}

(Sumber ; data primer)

Tabel 06

Distribusi dan Frekuensi Adanya Kristal Pada Urin Responden Berdasarkan Cara Konsumsi Air Hujan

\begin{tabular}{lccccc}
\hline & \multicolumn{3}{c}{ Cara Konsumsi Air Hujan } & \multirow{2}{*}{ Total } \\
\cline { 2 - 5 } & \multicolumn{2}{c}{ Masak Kompor } & \multicolumn{2}{c}{ Masak Tungku } & \\
\hline & Jumlah & $\%$ & Jumlah & $\%$ & \\
\hline Positif & 24 & 16,9 & 32 & 22,5 & 56 \\
\hline Negatif & 47 & 33,1 & 39 & 27,5 & 86 \\
\hline Total & 71 & 50 & 71 & 50 & 142 \\
\hline
\end{tabular}

(Sumber ; data primer) 


\section{Tabel 07}

Hubungan Antara Adanya Kristal pada Urin Responden dengan Jenis Tempat Mengalir Air Hujan (Talang)

\begin{tabular}{lccc}
\hline & Value & df & $\begin{array}{c}\text { Asymp. Sig. } \\
\text { (2-sided) }\end{array}$ \\
\hline $\begin{array}{l}\text { Pearson Chi- } \\
\begin{array}{l}\text { Square } \\
\text { N of Valid Cases }\end{array}\end{array}$ & 0,269 & 2 & 0,874 \\
\hline
\end{tabular}

(Sumber ; data primer)

Tabel 08

Hubungan Antara Adanya Kristal pada Urin Responden dengan Volume Air Hujan yang di Konsumsi

\begin{tabular}{lccc}
\hline & Value & df & $\begin{array}{c}\text { Asymp. Sig. } \\
(\text { 2-sided })\end{array}$ \\
\hline $\begin{array}{l}\text { Pearson Chi- } \\
\begin{array}{l}\text { Square } \\
\text { N of Valid Cases }\end{array}\end{array}$ & 0,048 & 1 & 0,827 \\
\hline
\end{tabular}

(Sumber; data primer)

Tabel 09

Hubungan Antara Adanya Kristal pada Urin Responden dengan Lamanya Konsumsi Air Hujan

\begin{tabular}{lccc}
\hline & Value & df & $\begin{array}{c}\text { Asymp. Sig. } \\
(\text { 2-sided })\end{array}$ \\
\hline Pearson Chi-Square & 3.354 & 1 & 0,067 \\
N of Valid Cases & 142 & & \\
(Sumber ; data primer) & & &
\end{tabular}

Tabel 10

Hubungan Antara Adanya Kristal pada Urine Responden dengan Cara Konsumsi Air Hujan

\begin{tabular}{lccc}
\hline & Value & df & $\begin{array}{c}\text { Asymp. Sig. } \\
\text { (2-sided) }\end{array}$ \\
\hline Pearson Chi-Square & 1.187 & 1 & 0,170 \\
\hline N of Valid Cases & 142 & & \\
\hline
\end{tabular}

(Sumber; data primer) 